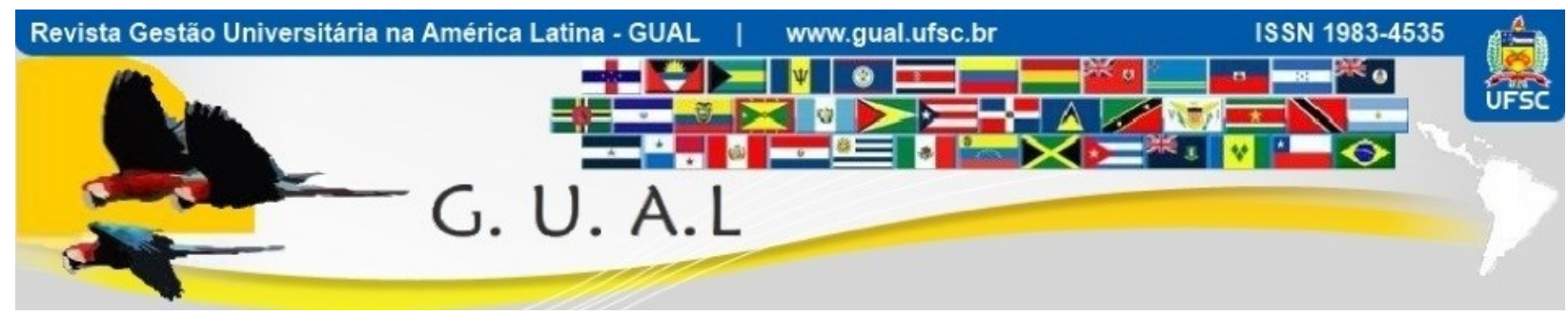

DOI: http://dx.doi.org/10.5007/1983-4535.2018v11n4p82

\title{
AÇÕES DE TREINAMENTO E DESENVOLVIMENTO DE PESSOAL COM FOCO NA INTERNACIONALIZAÇAO: UM ESTUDO NAS UNIVERSIDADES PÚBLICAS FEDERAIS BRASILEIRAS
}

TRAINING AND PERSONNEL DEVELOPMENT ACTIONS WITH A FOCUS ON INTERNATIONALIZATION: A STUDY IN THE BRAZILIAN FEDERAL PUBLIC UNIVERSITIES

Francisca Waleska Bruno Nunes, Mestre

Universidade Federal do Ceará - UFC waleskabn@bol.com.br

Ivana Serra Rodrigues Silva, Especialista Universidade Federal do Ceará - UFC ivanasrodrigues@gmail.com

Recebido em 24/novembro/2017

Aprovado em 06/setembro/2018

Sistema de Avaliação: Double Blind Review

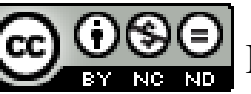

Esta obra está sob uma Licença Creative Commons Atribuição-Uso. 


\title{
RESUMO
}

É indiscutível a atuação da globalização sobre a economia mundial e seus efeitos em diversas esferas. Nesse contexto, as Instituições Federais de Ensino Superior (IFES) também sofrem influências e são impulsionadas à internacionalização universitária na busca de atender as demandas de ordem global. Este artigo tem o objetivo de pesquisar as ações desenvolvidas na área de Recursos Humanos direcionadas para o treinamento e desenvolvimento de staff (docentes e servidores técnicos-administrativos) com foco no processo de internacionalização nas Universidades Públicas Federais no Brasil. Esse estudo é descritivo e com abordagem qualitativa dos dados, foi realizado por meio de um questionário enviado por e-mail, no período de julho a dezembro de 2016, através do Serviço de Informação ao Cidadão (SIC) às 63 Universidades Públicas Federais Brasileiras. Após coletados os dados, foram classificadas de acordo com o modelo de categorias de desenvolvimento de staff de Rudzki (1998). Os resultados demonstraram que são diversas as ações que as universidades pesquisadas desenvolvem acerca de ações de treinamento e desenvolvimento de pessoas, contudo tais ações são praticadas por um número reduzido de universidades e que o referido modelo deve ser atualizado.

Palavras-chave: Internacionalização. Treinamento. Desenvolvimento. Staff Acadêmico.

\begin{abstract}
The globalization of the world economy and its effects in various spheres is indisputable. In this context, the Federal Institutions of Higher Education also suffer influences and are driven to university internationalization in the quest to meet global demands. This paper aims to research the actions developed in the area of Human Resources directed to the training and development of staff (teachers and technical-administrative servers) focused on the process of internationalization in the Federal Public Universities in Brazil. This research is descriptive with a qualitative approach, it was carried out through a questionnaire sent by e-mail, from July to December 2016, through the Citizen Information Service (CIS) to 63 Brazilian Federal Public Universities (BFPU). After the data were collected, they were classified according to Rudzki's model of staff development categories (1998). The results showed several actions of training and development of people that are developed by BFPU, however such actions are practiced by a few universities and Rudzki's model must be updated.
\end{abstract}

Keywords: Internationalization. Training. Development. Academic staff 


\section{INTRODUÇÃO}

A internacionalização das Instituições Federais de Ensino Superior (IFES) tem sido foco de inúmeras discussões no âmbito acadêmico, principalmente, por ser um tema complexo que tem reivindicado tanto compreensão do processo quanto definição de objetivos e planejamento estratégico, a fim de estimular e proporcionar o desenvolvimento das relações internacionais das universidades.

Segundo Knight e Wit (1997, p. 8), a internacionalização do ensino superior é “[...] the process of integrating an international/intercultural dimension into teaching, research and service functions of the institutions". De acordo com Stallivieri (2002), a internacionalização das instituições é o processo de introdução da dimensão internacional na cultura e na estratégia institucional, nas funções de formação, de investigação e de extensão e no processo de oferta e de capacidades da universidade.

No processo da internacionalização das IFES, há, em geral, uma preocupação com acordos internacionais, intercâmbios, ensino e extensão; contudo, segundo Rudzki (1998), o desenvolvimento da internacionalidade abrange todos os setores institucionais acadêmicos, inclusive o planejamento de ações de Recursos Humanos voltados para o treinamento e para o desenvolvimento do conhecimento e das habilidades de staff (professores e técnicos administrativos) com foco na internacionalização.

Marras (2011) define o treinamento como um processo de compreensão cultural que almeja transmitir ou reciclar conhecimentos, habilidades ou atitudes alusivas à execução de tarefas ou à sua otimização no ambiente laboral. Segundo o mesmo autor, o desenvolvimento está relacionado à melhoria e esta melhoria às ousadias conscientes, à velocidade nos processos decisórios, às habilidades, aos diversos conhecimentos, às atitudes e aos valores éticos.

Considerando a importância e complexidade do tema, objeto do presente estudo, chegou-se à problemática da pesquisa: Quais são as ações desenvolvidas na área de Recursos Humanos direcionadas para o desenvolvimento de staff com foco no processo de internacionalização nas Universidades Federais Brasileiras?

Como objetivo geral buscou-se investigar as principais ações de Recursos Humanos direcionadas para o treinamento e desenvolvimento do conhecimento e das habilidades de staff (constituído de docentes e de técnicos administrativos) com foco na Internacionalização das IFES brasileiras. Estabeleceu-se como objetivo específico identificar as ações de 
treinamento e desenvolvimento de pessoal com foco na internacionalização das universidades federais brasileiras de acordo com as categorias de Desenvolvimento de Staff de Rudzki (1998).

É qualitativa, pois não usa estatística robusta, e descritiva visto que visa à descrição, à análise, ao registro e à interpretação de dados. A unidade de análise bem como os sujeitos desta pesquisa são as 63 universidades federais brasileiras. A coleta de dados é de cunho secundário (bibliográfico) e primário (pesquisa por meio de questionamento eletrônico encaminhado através do Sistema de Informação ao Cidadão (SIC).

Esta pesquisa está organizada de forma a apresentar uma introdução do assunto com seus objetivos e relevância. Na sequência são apresentados o referencial teórico em que se discorre sobre a globalização e a internacionalização da educação superior, bem como sobre treinamento e desenvolvimento. Em seguida, a metodologia e a análise da pesquisa. $\mathrm{Na}$ finalização do trabalho, apresentam-se uma discussão sobre os dados obtidos, bem como a identificação de novas oportunidades de pesquisa oriundas das análises realizadas.

\section{FUNDAMENTAÇÃO TEÓRICA}

2.1 GLOBALIZAÇÕES, INTERNACIONALIZAÇÃO DA EDUCAÇÃO SUPERIOR E AÇÕES DE RECURSOS HUMANOS VOLTADOS PARA O TREINAMENTO E DESENVOLVIMENTO DE STAFF.

Segundo Knight (2008), globalização é o fluxo de tecnologia, conhecimento, pessoas, valores e ideias para além das fronteiras. A globalização afeta cada país em diferentes formas, modificando-lhes a história, a tradição, a cultura e as prioridades. Para a mesma autora, a internacionalização age como resposta à globalização. Para Bartell (2003), o autor define a internacionalização da educação como troca internacional de conhecimento, enquanto a globalização como fase que acelera a internacionalização da educação.

Tanto Knight (2008) quanto Bartell (2003), ao definirem globalização e internacionalização do ensino superior deixam claro que são duas vertentes complexas que possuem relação de interdependência econômica, financeira, político, social, educacional e cultural, contudo esses dois termos não devem ser confundidos.

O processo de internacionalização do ensino superior trouxe muitos desafios para as universidades, dentre eles a adequação do staff às exigências no mercado e mais investimento das universidades para a área de treinamento e desenvolvimento com foco na internacionalização. 
Segundo Ivancevich (2008), treinamento e desenvolvimento são processos que têm como objetivo proporcionar aos funcionários informação, capacitação e compreensão da organização e de suas metas. Além disso, destinam-se a ajudar o funcionário a continuar contribuindo de forma assertiva, com um bom desempenho.

Ainda, de acordo com Ivancevich (2008), treinamento é definido como um processo sistemático de alteração do comportamento do funcionário, visando a atingir as metas organizacionais, associadas às habilidades e às capacidades atuais do funcionário. Sua orientação é atual e ajuda o funcionário a dominar habilidades e capacidades específicas necessárias para o êxito no trabalho.

Para Araújo e Garcia (2014), o desenvolvimento está relacionado ao crescimento da pessoa em nível de conhecimento, habilidade e atitude. Shinyashiki (1998) apud Araújo e Garcia (2014), define desenvolvimento de RH como melhoria da qualidade de pessoal a fim de serem mais produtivos para o alcance dos objetivos organizacionais.

Aprendizagem organizacional pode ser entendida como o alcance de novos, múltiplos e contínuos conhecimentos sobre as dinâmicas e demandas corporativas, seja de maneira direta e/ou indireta, dentro e fora da empresa.

Para Knight (2005), as estratégias programáticas em nível institucional contemplam a área de recursos humanos na tríade conhecimentos, habilidades e atitudes, enfatizando que a mesma constitui um suporte para a Internacionalização, visto a complexidade envolvida desta no ensino superior.

Rudzki (1998) inclui em sua classificação do processo de internacionalização no nível institucional o desenvolvimento de staff, identificando as necessidades de mudança decorrentes do nível de complexidade das atividades dentro na instituição de ensino.

Para Knight (2005) e Rudzki (1998), a importância do desenvolvimento de ações na área de RH, é reconhecida e enfatizada como parte do processo de internacionalização, sendo inclusive, relacionadas à educação superior.

Embora utilizados como sinônimos ou muitas vezes confundidos, os conceitos de treinamento e desenvolvimento possuem focos distintos, sendo o primeiro precipuamente direcionado às atividades de um cargo, enquanto o segundo desenvolve talentos a fim de que possam tornar-se valiosos no futuro organizacional.

No Quadro 01, destacam-se as principais percepções relacionadas ao treinamento e desenvolvimento (T\&D). 
Quadro 1 Principais percepções relacionadas ao treinamento e desenvolvimento.

\begin{tabular}{|c|c|}
\hline Autoria & Percepções de treinamento e desenvolvimento \\
\hline $\begin{array}{l}\text { Milkovich e Boudreau } \\
\text { (2006) }\end{array}$ & $\begin{array}{l}\text { O treinamento é um processo sistemático para promover a aquisição } \\
\text { de habilidades, regras, conceitos ou atitudes que resultem em uma } \\
\text { melhoria da adequação entre as características dos empregados e as } \\
\text { exigências dos papéis funcionais. } \\
\text { O desenvolvimento é um processo em longo prazo para aperfeiçoar } \\
\text { as capacidades e motivações dos empregados a fim de torná-los } \\
\text { futuros membros valiosos da organização. O desenvolvimento inclui } \\
\text { não apenas o treinamento, mas também a carreira e outras } \\
\text { experiências. }\end{array}$ \\
\hline Reichel (2008) & $\begin{array}{l}\text { O T\&D vem justamente para dar apoio estratégico às empresas, } \\
\text { servindo como ferramenta de aperfeiçoamento de desempenho } \\
\text { organizacional por excelência. Mas isso deve enfrentar alguns } \\
\text { desafios, como, por exemplo: identificar talentos, treinar e } \\
\text { desenvolvê-los, patrocinar a criatividade, valorizar a atitude } \\
\text { empreendedora e fomentar avaliações. } \\
\text { (...) o setor de treinamento, quando conectado com o planejamento } \\
\text { estratégico, atinge suas funções básicas, que envolvem algum tipo de } \\
\text { mudança de comportamento em seus talentos. }\end{array}$ \\
\hline Hanashiro et al (2008) & $\begin{array}{l}\text { Treinamento é o aprimoramento do desempenho do funcionário para } \\
\text { que possa aumentar dos recursos - físicos, financeiros, informações, } \\
\text { sistemas etc. - colocados à disposição dele para realizar o seu } \\
\text { trabalho. É a preparação para levar uma pessoa a ser capaz de fazer } \\
\text { algo que nunca fez antes, mas sem a assistência de quem a ensinou. } \\
\text { Desenvolvimento remete à capacitação do empregado para alcançar } \\
\text { novas posições ou a gerência de negócios que envolvam a obtenção } \\
\text { de resultados cada vez mais abrangentes. }\end{array}$ \\
\hline Marras (2011) & $\begin{array}{l}\text { O treinamento tem como objetivo ensinar ou reciclar conhecimentos, } \\
\text { habilidades e atitudes diretamente relacionadas às tarefas e } \\
\text { atividades, ou sua otimização no trabalho, em curto prazo. } \\
\text { O desenvolvimento, segundo o mesmo autor, é um processo de } \\
\text { médio e longo prazo que busca despertar potencialidades visando a } \\
\text { metas e a resultados voltados ao desenvolvimento intelectual do } \\
\text { indivíduo. }\end{array}$ \\
\hline
\end{tabular}

Fonte: Elaborado pelas autoras.

A internacionalização, conforme Miura (2006), é um processo decorrente da globalização, sendo que esta última, demanda profissionais mais capacitados e qualificados para atuarem em um ambiente internacional. Para Souza e Guedes (2015), em sua pesquisa feita na Universidade Federal do Rio Janeiro sobre como a internacionalização da instituição impacta nos programas de capacitação destinados aos técnicos administrativos em educação que atuam exclusivamente em setores de relações internacionais, há uma carência de política de desenvolvimento desses servidores em consonância com as necessidades específicas que demandam as atividades que envolvem as relações internacionais. 
O Plano Nacional de Educação-PNE, aprovado pela Lei nº 13.005, publicada em 25 de junho de 2014, e prevê, dentre as metas, elevar gradualmente o número de matrículas na pós-graduação stricto sensu, de modo a atingir a titulação anual de mestres e doutores. Para o atingimento dessa meta, dentre outras, há que se destacar a estratégia de "consolidar programas, projetos e ações que capacitem o staff universitário à internacionalização da pesquisa e da pós-graduação brasileiras, incentivando a atuação em rede e o fortalecimento de grupos de pesquisa". (BRASIL, 2014).

Assim, é importante ressaltar que a internacionalização do ensino superior é um objetivo a ser perseguido, com amparo legal, e não apenas uma expectativa. A necessidade está embasada principalmente na socialização e disseminação dos diferentes modos de conhecimento e cultura inerentes à atualidade.

O autor Rudzki (1998) elaborou um modelo de Internacionalização universitária denominado modelo Fractal de Internacionalização de IES - Rudzki (1998), que é composto de seis etapas: contexto, abordagens, razões, ações-dimensões-stividades (mudança organizacional, inovação curricular, desenvolvimento de equipe e mobilidade estudantil), monitoramento e revisão periódica, reposicionamento-realianhamento. O desdobramento do item 4, a alínea "c", Desenvolvimento de staff, será o foco desta pesquisa.

A Figura 01 e o Quadro 02 exemplificam o Modelo Fractal de Internacionalização de IES, Rudzki (1998). Os Quadros 3 e 4 esclarecem a origem dos tópicos relacionados ao Desenvolvimento de staff de Rudzki (1998).

Figura 1 Modelo Fractal de Internacionalização de IES, Rudzki (1998).

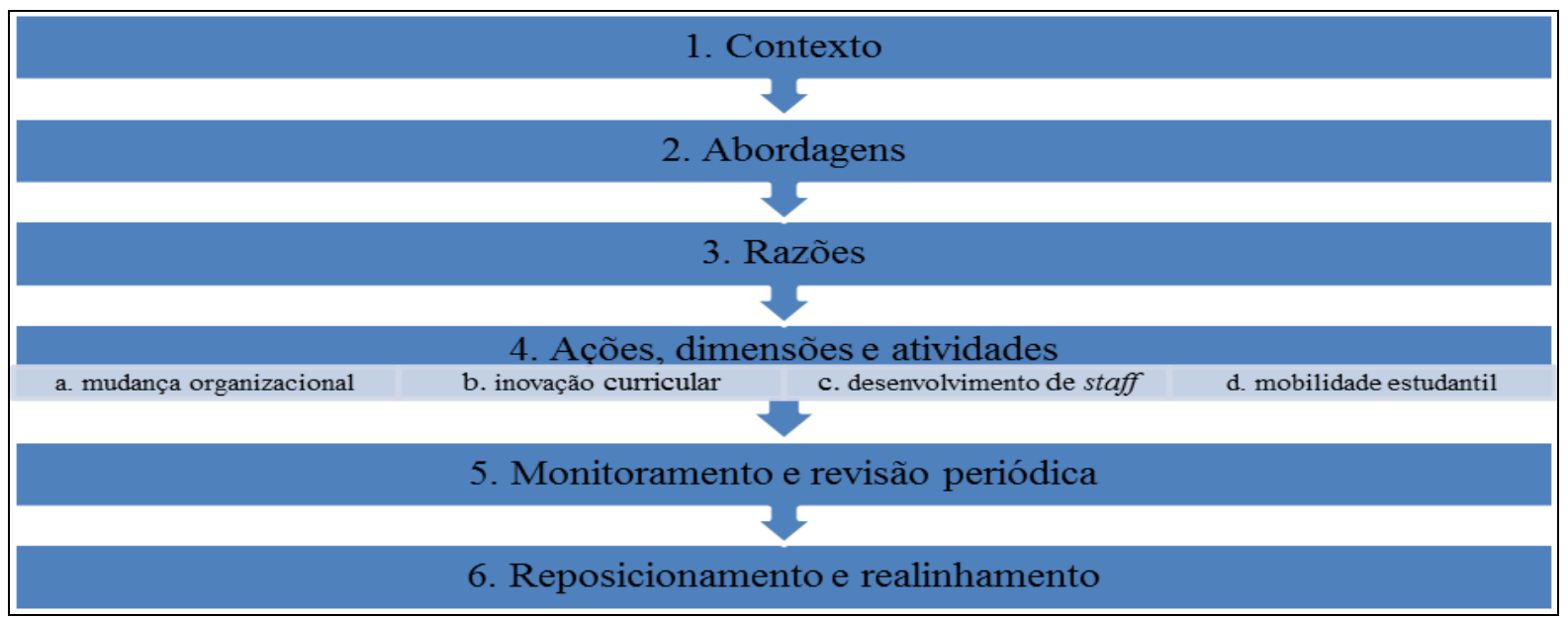

Fonte: Rudzki (1998) adaptado. 
O Quadro 02 explana cada tópico referente ao modelo de internacionalização universitária apresentado.

Quadro 2 Conceitos do Modelo Fractal de Internacionalização de IES, Rudzki (1998).

\begin{tabular}{|c|c|l|}
\hline 1 & Contexto & $\begin{array}{l}\text { Refere-se aos ambientes institucional, nacional e internacional das } \\
\text { instituições de ensino. }\end{array}$ \\
\hline 2 & Abordagem & $\begin{array}{l}\text { Pode ser classificada entre internacionalização proativa (existência de } \\
\text { uma política ou estratégia explícita), internacionalização reativa ou } \\
\text { passiva (resposta aos fatores externos), internacionalização oculta (as } \\
\text { atividades são realizadas por indivíduos que não possuem apoio oficial } \\
\text { ou institucional) e a ausência de internacionalização (caracterizada pela } \\
\text { ausência de ações ou por falta interesse). }\end{array}$ \\
\hline 3 & Razões & As mais diversas motivações internas e externas. \\
\hline 4 & $\begin{array}{c}\text { Ações, dimensões e } \\
\text { atividades }\end{array}$ & $\begin{array}{l}\text { a) Mudança organizacional - adaptação ao ambiente; } \\
\text { b) Inovação curricular - inserção de línguas estrangeiras no currículo; } \\
\text { c) Desenvolvimento de staff - desenvolvimento profissional de } \\
\text { docentes e de funcionários administrativos (grifo nosso); e, } \\
\text { d) Mobilidade estudantil - mobilidade física e intelectual. }\end{array}$ \\
\hline 5 & $\begin{array}{c}\text { Monitoramento e } \\
\text { Revisão periódica }\end{array}$ & $\begin{array}{l}\text { Avaliação da efetividade dos programas e ações de internacionalização } \\
\text { realizada pela instituição. }\end{array}$ \\
\hline 6 & $\begin{array}{c}\text { Reposicionamento e e } \\
\text { realinhamento }\end{array}$ & $\begin{array}{l}\text { Após a avaliação dos programas e ações de internacionalização é feito } \\
\text { o reposicionamento da política de internacionalização da instituição. }\end{array}$ \\
\hline
\end{tabular}

Fonte: Rudzki (1998) adaptado.

O presente trabalho tem o embasamento no "Desenvolvimento de staff" apresentado no Quadro 03 que é o desdobramento do item 4, alínea “c”, do Quadro 02 do modelo em epígrafe. Destacam-se no Quadro 04 as categorias relacionadas ao "Desenvolvimento de staff" (docentes e funcionários administrativos).

Quadro 3 Ações, dimensões e atividades.

\begin{tabular}{|c|c|}
\hline $\begin{array}{c}\text { Ações, dimensões } \\
\text { e atividades }\end{array}$ & Atividades \\
\hline $\begin{array}{l}\text { a) Mudança } \\
\text { organizacional }\end{array}$ & $\begin{array}{l}\text { - Comprometimento Institucional com a internacionalização como resultado } \\
\text { de uma política estratégica, alocação de recursos e plano operacional; } \\
\text { - Estabelecimento de redes externas em nível institucional, acadêmico, } \\
\text { departamental e individual; } \\
\text { - Franchising de cursos; } \\
\text { - Estabelecimento de cursos conjuntos com outras instituições; } \\
\text { - Administrar ações internacionais e o desenvolvimento de professores. }\end{array}$ \\
\hline $\begin{array}{l}\text { b) Inovação no } \\
\text { Currículo }\end{array}$ & $\begin{array}{l}\text { - Ensino compulsório de segunda língua para estudantes e suporte linguístico } \\
\text { para estudantes internacionais; } \\
\text { - Desenvolver novos programas (Negócios Internacionais, Direito, União } \\
\text { Europeia e RI); } \\
\text { - Introdução de novos módulos e novos imputs em programas existentes. }\end{array}$ \\
\hline
\end{tabular}




\begin{tabular}{|c|c|}
\hline $\begin{array}{l}\text { Ações, dimensões } \\
\text { e atividades }\end{array}$ & Atividades \\
\hline $\begin{array}{c}\text { c) } \\
\text { Desenvolvimento } \\
\text { de staff } \\
\text { (grifo nosso) }\end{array}$ & $\begin{array}{l}\text { - Profissionalização de administradores que lidam com questões } \\
\text { internacionais; } \\
\text { - Treinamento de professores para lecionar em classes multiculturais; } \\
\text { - Estabelecimento de anos sabáticos para professores (atividades } \\
\text { internacionais); } \\
\text { - Trabalho com professores e pesquisadores estrangeiros em instituições } \\
\text { domésticas e/ou internacionais); } \\
\text { - Incentivo à mobilidade internacional física de professores em programas } \\
\text { nacionais e/ou transnacionais; } \\
\text { - Consciência dos riscos (evasão de cérebros); } \\
\text { - Alocação de recursos que permitam ao corpo acadêmico participar de } \\
\text { conferencias, seminários, congressos, etc. (em nível internacional). }\end{array}$ \\
\hline $\begin{array}{l}\text { d) Mobilidade de } \\
\text { estudantes }\end{array}$ & $\begin{array}{l}\text { - Viagens campo internacional (ligadas à disciplina); } \\
\text { - Intercâmbio de estudantes via programa Fullbright, Alban; } \\
\text { - Desenvolvimento de mecanismo de transferência de créditos; } \\
\text { - Desenvolvimento de habilidades linguísticas (idioma estrangeiro } \\
\text { compulsório em todos os programas); } \\
\text { - Entendimento dos procedimentos de concessão de vistos para estudantes. }\end{array}$ \\
\hline
\end{tabular}

Fonte: Rudzki (1998) adaptado.

Quadro 4 Categorias de Desenvolvimento de staff Rudzki (1998).

a) Profissionalização de administradores que lidam com questões internacionais;

b) Treinamento de professores para lecionar em classes multiculturais;

c) Estabelecimento de anos sabáticos para professores (atividades internacionais);

d) Trabalho com professores e pesquisadores estrangeiros em instituições domésticas e/ou internacionais);

e) Incentivo à mobilidade internacional física de professores em programas nacionais e /ou transnacionais);

f) Consciência dos riscos (evasão de cérebros);

g) Alocação de recursos que permitam ao corpo acadêmico participar de conferências, seminários, congressos, etc. (em nível internacional).

Fonte: Rudzki (1998) adaptado.

Conforme a Organização das Nações Unidas para a Educação, a Ciência e a Cultura (2003), as instituições de educação superior estão cada vez mais conscientes do fato de que, para envolver-se em esquemas de internacionalização, precisam estar preparadas para enfrentar uma dura competição.

Para Santos e Madeira (2016), a internacionalização acadêmica não é um processo com dinâmica e ritmo únicos, sendo constituído com as variações de investimentos, possibilidades e dinâmicas próprias.

Segundo Borges-Andrade (2006), dentro do campo de treinamento, desenvolvimento e educação, o que se busca é a facilitação da aprendizagem de competências relacionadas ao 
desempenho ocupacional. Assim, as universidades que buscam consolidar as ações no sentido de treinamento e desenvolvimento de servidores estão em consonância com as perspectivas internacionais.

De acordo com Freire Júnior (2014), os processos de internacionalização nas instituições de maior prestígio no mundo atuam de forma estratégica e integrada, contando para isso com unidades e equipes profissionais que atuam em diferentes setores para responderem às diversas atividades desenvolvidas com objetivos bem definidos.

\section{METODOLOGIA}

Considerando o objetivo de investigar as ações desenvolvidas na área de Recursos Humanos direcionadas para o desenvolvimento de staff com foco no processo de internacionalização nas Universidades Federais brasileiras, trata-se de uma pesquisa descritiva.

Quanto ao procedimento, inicialmente foi realizada pesquisa bibliográfica, explorando-se a literatura disponível, nacional e estrangeira, no sentido de embasar os aspectos teóricos do estudo, em seguida, partiu-se para o recolhimento de dados primários, utilizando, como instrumento de coleta, o formulário on line do SIC - Sistema de Informação ao Cidadão.

Nesse sistema, foi enviada a todas as universidades públicas brasileiras, total de 63 universidades, no período de julho a dezembro de 2016, a seguinte pergunta: "Quais são as ações desenvolvidas na área de Recursos Humanos direcionadas para o desenvolvimento de staff, com foco no processo de internacionalização, realizadas pela Universidade?”. Em um segundo momento, os dados obtidos foram classificados de acordo com as categorias de Desenvolvimento de staff de Rudzki (1998).

Após a tabulação dos dados primários, realizou-se uma análise geral das principais ações desenvolvidas na área de Recursos Humanos direcionadas para o desenvolvimento de staff, com foco no processo de internacionalização, realizadas pelas universidades.

\section{APRESENTAÇÃO DOS RESULTADOS}

Os dados, obtidos nas respostas dos formulários on line do SIC - Sistema de Informação ao Cidadão, enviados com a seguinte pergunta: “Quais são as ações desenvolvidas na área de Recursos Humanos direcionadas para o desenvolvimento de staff, com foco no 
processo de internacionalização, realizadas pela Universidade?”, foram representados conforme a Tabela 01 e Gráfico 01.

Tabela 1 Ações desenvolvidas na área de Recursos Humanos pelas Universidades Públicas Federais brasileiras.

$\begin{aligned} & \text { AÇÕES DE DESENVOLVIMENTO DE STAFF, } \\ & \text { COM FOCO NO PROCESSO DE }\end{aligned}$
$\begin{aligned} & \text { NÚMERO DE } \\ & \text { INTERNACIONALIZAÇÃO. }\end{aligned}$

Fonte: Dados da pesquisa.

Gráfico 1 Ações desenvolvidas na área de Recursos Humanos pelas Universidades públicas federais brasileiras.

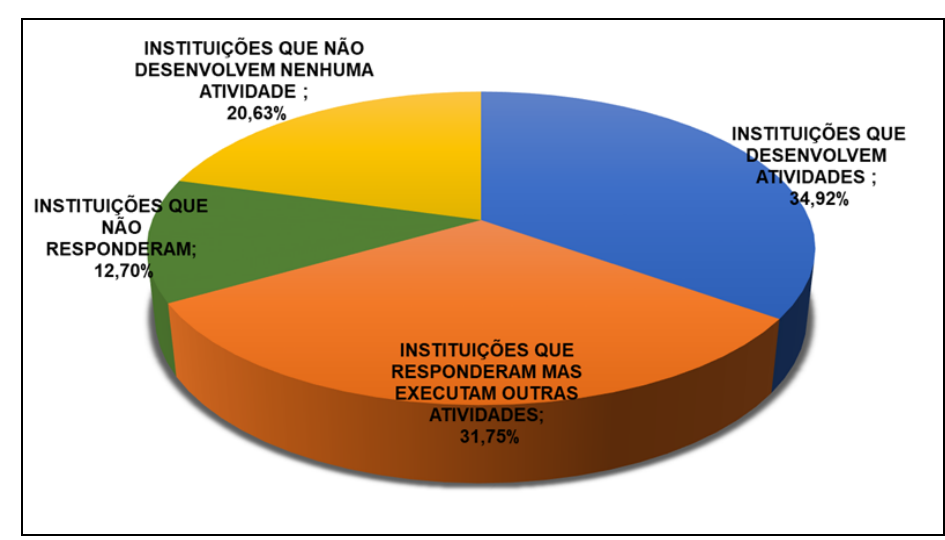

Fonte: Dados da pesquisa.

Analisando, especificamente, as repostas das 22 (ou 34,92\%) universidades que desenvolvem alguma atividade/ação de recursos humanos com foco na internacionalização das universidades, chegou-se aos dados constantes na Tabela 02 que traz a classificação dessas ações consoante as categorias de Desenvolvimento de staff de Rudzki (1998), atendendo, dessa forma aos objetivos geral e específico desta pesquisa. 
Tabela 02 Identificação e categorização das ações de treinamento e desenvolvimento de RH praticadas pelas 22 universidades federais brasileiras.

\begin{tabular}{|c|c|c|c|c|}
\hline $\begin{array}{c}\text { CATEGORIAS DE } \\
\text { DESENVOLVIMENTO } \\
\text { DE STAFF } \\
\text { RUDZKI (1998) } \\
\end{array}$ & $\begin{array}{l}\text { AÇÕES DE DESENVOLVIMENTO E TREINAMENTO } \\
\text { PRATICADAS PELAS UNIVERSIDADES }\end{array}$ & QUANTIDADE DE AÇÕES & $\begin{array}{c}\text { NÚMERO DE INSTITUIÇÕES QUE } \\
\text { PRATICAM ALGUMA DAS AÇÕES } \\
\text { RELACIONADAS ÀS CATEGORIAS DE } \\
\text { RUDZKI (1998) } \\
\end{array}$ & $\begin{array}{l}\text { PORCENTAGEM } \\
\text { DAS INSTITUIÇÕES }\end{array}$ \\
\hline $\begin{array}{l}\text { a) Profissionalização de } \\
\text { administradores que } \\
\text { lidam com questões } \\
\text { internacionais }\end{array}$ & 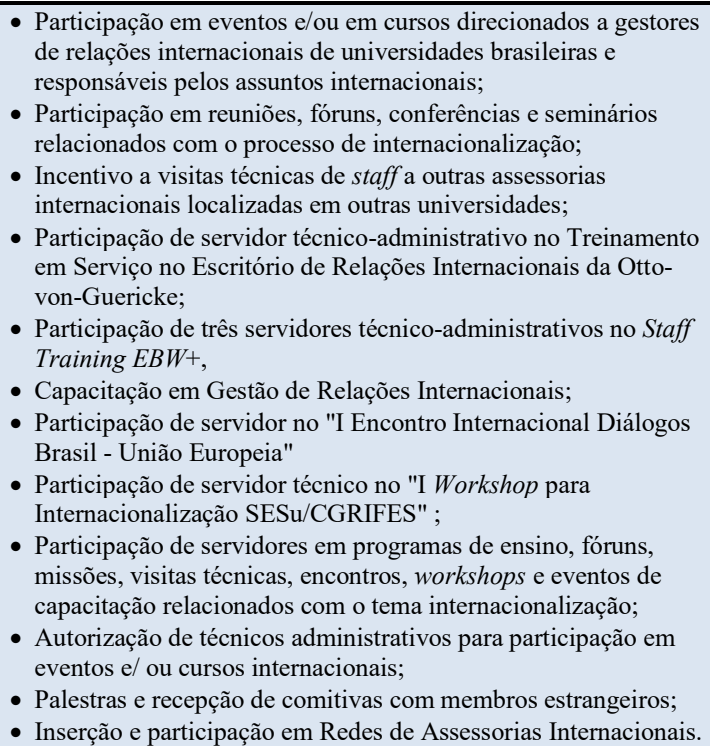 & 12 & 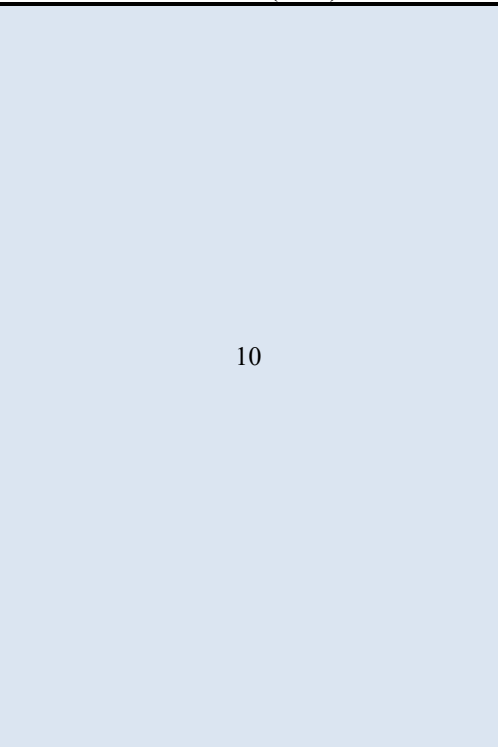 & 45.45 \\
\hline $\begin{array}{l}\text { b) Treinamento de } \\
\text { professores para lecionar } \\
\text { em classes multiculturais }\end{array}$ & $\begin{array}{l}\text { - Programa Research Connect do Conselho Britânico e Fundo } \\
\text { Newton -via FAPES para treinamento de professores; } \\
\text { - Oficina/Curso de English as a Medium of Instruction-EMI } \\
\text { oferecida aos docentes como parte do Programa de } \\
\text { Capacitação; } \\
\text { - Curso de introdução e de difusão da cultura e história africana; } \\
\text { - Curso de formação à docência que contempla em seus objetivos } \\
\text { o fomento de atividades voltadas à internacionalização. }\end{array}$ & 04 & 04 & 18.18 \\
\hline $\begin{array}{l}\text { c) Estabelecimento de } \\
\text { anos sabáticos para } \\
\text { professores (atividades } \\
\text { internacionais) }\end{array}$ & 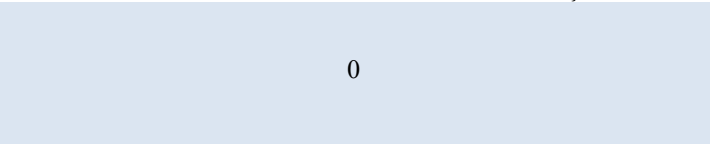 & 0 & 0 & 0 \\
\hline
\end{tabular}


AÇÕES DE TREINAMENTO E DESENVOLVIMENTO DE PESSOAL COM FOCO NA INTERNACIONALIZAÇAO: UM ESTUDO NAS UNIVERSIDADES PÚBLICAS FEDERAIS BRASILEIRAS

DOI: http://dx.doi.org/10.5007/1983-4535.2018v11n4p82

\begin{tabular}{|c|c|c|c|c|}
\hline $\begin{array}{l}\text { d) Trabalho com } \\
\text { professores e } \\
\text { pesquisadores } \\
\text { estrangeiros em } \\
\text { instituições domésticas } \\
\text { e/ou internacionais }\end{array}$ & $\begin{array}{l}\text { - Visitas técnicas; } \\
\text { - Missões no exterior; } \\
\text { - Programas de intercâmbio; } \\
\text { - Estágio profissional e praticas e saberes com comunidades } \\
\text { internacionais; } \\
\text { - Estágios linguísticos e culturais em diversos países para } \\
\text { servidores docentes. }\end{array}$ & 05 & 09 & 40.90 \\
\hline $\begin{array}{l}\text { e) Incentivo à mobilidade } \\
\text { internacional física de } \\
\text { professores (programas } \\
\text { nacionais e } \\
\text { transnacionais) }\end{array}$ & $\begin{array}{l}\text { - Autorização de afastamento de docentes para participação em } \\
\text { eventos e/ou em cursos internacionais; } \\
\text { - Incentivo à mobilidade internacional física de professores; } \\
\text { - Vagas para servidores em pós-graduação sanduíche em parceria } \\
\text { com diversos países; } \\
\text { - Mestrado ou doutorado em instituições estrangeiras. }\end{array}$ & 04 & 13 & 59,09 \\
\hline $\begin{array}{l}\text { f) Consciência dos riscos } \\
\text { (evasão de cérebros) }\end{array}$ & 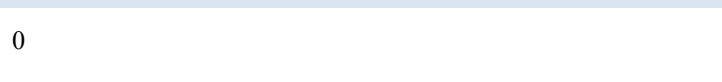 & 0 & 0 & 0 \\
\hline $\begin{array}{l}\text { g) Alocação de recursos } \\
\text { que permitam ao corpo } \\
\text { acadêmico participar de } \\
\text { conferências, seminários, } \\
\text { congressos, etc. (em nível } \\
\text { internacional) }\end{array}$ & $\begin{array}{l}\text { - Pagamento de diárias; } \\
\text { - Auxílio financeiro com passagens; } \\
\text { - Pagamento de inscrição para eventos internacionais; } \\
\text { Pagamento de inscrição em projetos de pesquisa, } \\
\text { desenvolvimento e inovação; } \\
\text { - Custeio de matrícula e/ou mensalidade em universidades no } \\
\text { exterior. }\end{array}$ & 05 & 04 & 18,18 \\
\hline
\end{tabular}

Fonte: Dados da pesquisa. 
A Tabela 02 demonstra que o maior número de ações de $\mathrm{RH}$ desenvolvidas para internacionalização universitária está voltada para a categoria a) "Profissionalização de administradores que lidam com questões internacionais" apresentando 12 tipos de ações. Infere-se dessa informação uma preocupação das universidades de capacitar e desenvolver as habilidades dos profissionais que trabalham diretamente com assuntos internacionais. Embora a citada categoria tenha sido representada com o maior número e diversificação de ações, não é a categoria mais praticada pelas universidades, visto que apenas 10 universidades praticam alguma ação relacionada a essa categoria.

A categoria "e) Incentivo à mobilidade internacional física de professores (programas nacionais e transnacionais" é a mais representativa quanto ao número de universidades; contudo, não em quantidade e variedade de ações. As categorias "b) Treinamento de professores para lecionar em classes multiculturais" e "g) Alocação de recursos que permitam ao corpo acadêmico participar de conferências, seminários, congressos, etc. (em nível internacional)" aparecem citadas por um menor quantitativo de universidades, mas demonstram, respectivamente, a preocupação com a diversidade cultural encontrada nas universidades e a importância da alocação de recursos financeiros para viabilizar as mais variadas ações de RH com foco na internacionalização. Em relação as categorias “c) Estabelecimento de anos sabáticos para professores (atividades internacionais)" e "f) Consciência dos riscos (evasão de cérebros)", não se obteve respostas.

A Tabela 03 demonstra as ações de treinamento e desenvolvimento de staff não estão contempladas nas categorias de Rudzki (1998). A maioria dessas ações está voltada para o ensino de línguas estrangeiras. Destacam-se os cursos de idiomas praticados em 27 universidades federais. 
Tabela 3 Ações diversas de desenvolvimento e treinamento com foco na internacionalização universitária

\begin{tabular}{lll}
\hline $\begin{array}{l}\text { Diversas ações de desenvolvimento } \\
\text { Treinamento }\end{array}$ & $\begin{array}{l}\text { Quantidade } \\
\text { de ações }\end{array}$ & $\begin{array}{l}\text { Número de instituições que } \\
\text { praticam açóes de rh com foco } \\
\text { na internacionalização }\end{array}$ \\
\hline $\begin{array}{l}\text { •IsF (Idiomas sem Fronteiras); } \\
\text {-Teste de proficiência TOEFL ITP; }\end{array}$ & 09 \\
•Cursos de idiomas aos servidores; & 05 \\
•Teste de nivelamento de língua inglesa; & 27 \\
•Parceria PRONATEC servidor (presencial e & 04 \\
$\quad$ distância); & 02 \\
•Oficinas para professores de pós-graduação & 01 \\
que enfocaram a leitura, escrita e & \\
apresentação. & 11 \\
•Promoção de acordos internacionais & 01 \\
•Evento de redação científica internacional & \\
\hline
\end{tabular}

Fonte: Dados da pesquisa.

\section{CONCLUSÃO}

Constatou-se com esta pesquisa que as principais ações adotadas para o desenvolvimento e treinamento de staff com foco na internacionalização universitária das universidades federais brasileiras estão focadas, principalmente, no incentivo à mobilidade física internacional de professores (programas nacionais e transnacionais), para a profissionalização de administradores que lidam com questões internacionais para o trabalho com professores e pesquisadores estrangeiros em instituições domésticas e/ou internacionais. A pesquisa demonstrou, ainda, que há pouca atenção referente aos tópicos treinamento de professores para lecionar em classes multiculturais e alocação de recursos, e nenhuma ação referente à consciência de riscos.

Contudo, apesar de haver um interesse e investimento na área de recursos humanos para desenvolvimento e treinamento de staff universitário que vise à promoção da internacionalidade da educação superior, as universidades ainda têm um importante desafio no fomento de ações e estratégias que englobem a internacionalização como uma demanda necessária, urgente e atual para o desenvolvimento, reconhecimento e inserção das academias no contexto internacional.

Acerca do modelo teórico adotado (RUDZKI, 1998), ressalta-se que as categorias de ações de staff apresentadas são poucas e devem ser ampliadas, pois há diversas outras atividades, tais como cursos de línguas estrangeiras, workshops, cursos de celebração de acordos bilaterais, ou, mesmo, minicursos de relações internacionais que não estão 
contemplados estão contempladas no modelo supracitado. Esse estudo ainda é incipiente, sugere-se a aplicação da pesquisa em um número maior de universidades e, principalmente, que ampliem as categorias de ações de staff com foco para internacionalização universitária.

\section{REFERÊNCIAS}

ARAUJO, L. C. G., GARCIA. A. A. Gestão de pessoas: estratégias e integração organizacional. $2^{\mathrm{a}}$ ed. São Paulo: Atlas, 2014.

BARBALHO, M. G. C. A internacionalização da educação superior: o papel da Universidade. 2007. Disponível em:

$<$ http://www.anpae.org.br/congressos_antigos/simposio2007/295.pdf $>$ Acesso em: 03 jun. 2016.

BARTELL, M. Internationalization of universities: a university culture-based framework. The International Journal of Higher Education Research, Winnipeg, v.45, p. 43-70, jan. 2003. Disponível em: <http://link.springer.com/article/10.1023\%2FA\%3A1021225514599> Acesso em: 03 jun. 2016.

BORGES-ANDRADE, J. E. et al. Treinamento, desenvolvimento e educação em organizações e trabalho: fundamentos para a gestão de pessoas. Porto Alegre: Artmed, 2006.

BRASIL. INEP - Instituto Nacional de Estudos e Pesquisas em Educacionais Anísio Teixeira. Plano Nacional de Educação - PNE 2014-2024. Brasília, DF: INEP, 2014. Disponível em: $<$ http://www.publicacoes.inep.gov.br/portal/download/1362 >. Acesso em: 19 de maio de 2017.

CERVO, Amado Luiz; BERVIAN, Pedro Alcino; SILVA, Roberto da. Metodologia científica. 6. ed. São Paulo, SP: Prentice Hall, 2007.

CHRISTINO, A. M. Internacionalização de ensino superior: estudo de casos em curso de administração de instituições públicas de ensino superior. 2013. $128 \mathrm{f}$. Trabalho de conclusão de curso (Tese de Doutorado). Universidade de São Paulo. 2013.

Disponível em: <http://www.teses.usp.br/teses/disponiveis/96/96132/tde-13012014111919/pt-br.php> Acesso em: 17 out. 2016.

CRESWELL, John W. Projeto de Pesquisa: métodos qualitativo e quantitativo. 3. ed., Porto Alegre: Penso, 2012.

FREIRE, J. C. Internacionalização de Instituições de Ensino Superior no Brasil. Unesp Ciência. Edição 62. 2015. Disponível em: <http://www.unespciencia.com.br/?p=1343> Acesso em 14. mai. 2017.

GIL, A. C. Como elaborar projetos de pesquisa. 4. ed. São Paulo: Atlas, 2007. 
HANASHIRO et al. Gestão do fator humano: uma versão baseada em stakeholders. 2. ed. São Paulo: Saraiva, 2008.

IVANCEVICH, John. M. Gestão de recursos humanos. São Paulo: McGraw-Hill, 2008.

KIGHT, J., and WIT, H. de. Internationalization of Higher Education in Asia Pacific Countries, Amsterdam: European Association for International Education, 1997.

Disponível em:

$<$ https://books.google.com.br/books/about/Internationalisation_of_higher_education.html?id= S3cOAQAAMAAJ\&redir_esc=y > Acesso em: 03 nov. 2016.

KINGHT, J. An internationalization model: responding to new realities and challenges. 2005. In H. de Wit et al. (Eds.), Internationalization of higher education in Latin America: the international dimension. Washington DC, WA: World Bank.

Disponível em:

$<$ http://siteresources.worldbank.org/EXTLACREGTOPEDUCATION/Resources/Higher_Ed in_LAC_Intnal_Dimension.pdf> Acesso em: 03 nov. 2016.

KINGHT, J. Higher education in turmoil: the changing world of internationalization. Rotterdam: Sense Publishers, 2008. Disponível em: https://www.sensepublishers.com/media/475-higher-education-in-turmoil.pdf Acesso em: 05 jun. 2016.

MAY, Tim. Pesquisa social: questões, métodos e processos. Tradução Carlos Alberto Silveira Netto Soares. 3. ed., Porto Alegre: Artmed, 2004.

MARRAS, Jean Pierre. Administração de recursos humanos: do operacional ao estratégico. São Paulo: Saraiva, 2011.

MILKOVICH, G. T.; BOUDREAU, J. W. Administração de recursos humanos. 1 ed. São Paulo: Atlas.

MIURA, Irene Kazumi. O processo de internacionalização da Universidade de São Paulo: um estudo em três áreas de conhecimento. 2009. $191 \mathrm{f}$. Trabalho de conclusão de curso (Tese de Doutorado) - Faculdade de Economia, Administração e Contabilidade de Ribeirão Preto. Ribeirão Preto, 2009. Disponível em:

$<$ http://www.teses.usp.br/teses/disponiveis/livredocencia/96/tde-03102006-135941/pt-br.php> Acesso em: 08 nov. 2016.

MORISINI, Marília Costa. Estado do conhecimento sobre internacionalização da educação superior: conceitos e práticas. Educar em revista, n. 28, p. 107-124, 2006. Disponível em: $<$ http://www.scielo.br/pdf/er/n28/a08n28.pdf > Acesso em: 02 nov. 2015.

REICHEL, Harduin. Treinamento e desenvolvimento. Curitiba: IESDE BRASIL S.A., 2008.

RUDZKI, R. E. J. The strategic management of internationalization: towards a model of theory and practice. 1998. 166 f. University of Newcastle, UK, 1998. 
Disponível em: <https://theses.ncl.ac.uk/dspace/handle/10443/149> Acesso em: 02 abr. 2017.

SANTOS, Ely Guimarães dos. A UNESCO e o mundo da cultura. Campinas, SP: [s.n.], 1999.

SANTOS, André Luis Marenco dos; MADEIRA, Rafael Machado. Os desafios da internacionalização: mapeando dinâmicas e rotas da circulação internacional. Revista Brasileira de Ciência Política, 2016.

SNELL, S.; BOHLANDER, G. Administração de recursos humanos. Tradução Maria Lúcia G. Leite Rosa e Solange Aparecida Visconti. São Paulo: Cenange Learning, 2009.

SOUZA, Izabel Dias; GUEDES, Ana Lucia. A internacionalização do Ensino Superior: impactos no corpo técnico administrativo. Almanaque Multidisciplinar de Pesquisa, v. 1, n. $1,2015$.

STALLIVIERI, L. A internacionalização nas universidades brasileiras: o caso da universidade de Caxias do Sul. 2002. 90 f. Trabalho de Conclusão de Curso (Mestrado) Universidade de São Marcos, São Paulo, 2002. Disponível em:

$<$ http://www.academia.edu/22707105/Estrat\%C3\%A9gias_de_Internacionaliza $\% \mathrm{C} 3 \% \mathrm{~A} 7 \% \mathrm{C}$ 3\%A3o_das_Universidades_Brasileiras_-_Livro> Acesso em: 02 abr. 2017.

WIT, H. de. Changing rationales for the internationalization of higher education. In DE WET, H. Internationalization of higher education: in institutional perspective. Bucharest, Romania: UNESCO/CEPES, 2000. Disponível em:

$<$ http://unesdoc.unesco.org/images/0012/001222/122253eo.pdf $>$ Acesso em: 10 jun. 2016. 